\title{
Code-mixing in the FM Radio in Bangladesh: A Sociolinguistic Observation
}

\author{
Md Iqbal Hosain*
}

\begin{abstract}
This paper deals with code-mixing used in the FM radio of Bangladesh. Code-mixing, a term in sociolinguistics, refers to the hybridization of two languages in a bilingual context. Of late, in the FMs of Bangladesh, the Radio Jockeys and the callers have frequently been mixing Bengali and English codes in their various programs. It is supposed to be the liberalization of the air waves that leads to the shifting of language in broadcasting by the RJs. In this paper, the researcher intends to extrapolate the motivations for codemixing, and see whether the specific extralinguistic factors contribute to such code-mixing. Data from naturally occurring announcements and conversations were recorded from the four main radio stations, and then transcribed into English for analysis.
\end{abstract}

\section{Introduction}

Code-mixing, nowadays, has been a common phenomenon in various sociolinguistic contexts. In this age of globalization, the world is gradually becoming a small village and the linguistic freedom is also getting unbound. Moreover, a group of modern linguists have come out with liberal notions to accredit any sort of linguistic diversity such as code-mixing, diglossia, nativization etc. This liberal linguistic practice is seen in various domains such as electronic and print media of Bangladesh. In the FMs of Bangladesh, the RJs are seen frequently to use Bengali and English codes in their lively anchoring.

\footnotetext{
* Assistant Professor, Dept. of English Language and Literature, International Islamic University Chittagong, Dhaka Campus.
} 


\section{The Inception of FM Radios in Bangladesh}

The history of FM radio in Bangladesh dates approximately four years back and the first FM radio is Radio Today (98.6 FM). The advent of FM brings a new dimension in the electronic media, and creates a new zeal and enthusiasm in the mind of the people, especially young generation. Now there are six FM radios doing their operations throughout the country with various innovative programs and news. They have already taken their positions in the field of electronic media and proceed towards their desired goal. The four main radio channels are chosen to conduct the research and so a brief history of these FMs is described below:

\section{Radio Today FM 89.6:}

This is the first FM radio in Bangladesh to be considered as the pioneer in the field of FM radio in Bangladesh launched on 15 September 2006 with 24 hour broadcast. The station turned out to be a massive success among people from all walks of life.

\section{Radio Foorti FM 88.0:}

Radio Foorti which began their transmission in September 21, 2006 has managed to affirm a strong foothold amongst the radio lovers. The aim of Radio Foorti is to entertain the listeners. 'We just want to supply our listener's foorti (fun),' says Sabbir Ahmed, associate producer and an RJ of Radio Foorti.

\section{Radio Amar:}

Radio Amar is another leading FM radio station in Bangladesh, launched on 11 December 2007 with the slogan 'True voice of Bangladesh'. It broadcasts on 88.4 FM. In this channel news, music, and various programs are broadcast.

\section{Radio ABC:}

ABC Radio is the first news-oriented FM radio station in Bangladesh. It is one of the sister concerns of the Transcom Group. The station studio is located at the media area of Kawran Bazar. (Wikipedia) 


\section{Review of Literature}

The term code-mixing refers to the use of one or more languages for consistent transfer of linguistic units from one language into another, and by such a mixture developing a new restricted---or not so restricted code of linguistic interaction. Such 'mixed' codes have developed in several language areas in South Asia (Kachru 1977)

Wardhaugh (1992:107) says, "Conversational code-mixing involves the deliberate mixing of two languages without an associated topic change."

Hudson (1996:53) defines code-mixing as a case "where a fluent bilingual talking to another fluent bilingual changes language without any change at all in the situation." He also says, "To get the right effect the speakers balance the two languages against each other as a kind of linguistic cocktail."

In Bangladesh there are different kinds of Bengali-English code switching, involving partial and complete transfers from English. These hybrid varieties of code-switching are in a complex relationship with national language policy in Bangladesh, which prescribes the use of Bengali in public life. (Banu \& Sussex 2001, 51)

According to Blom and Gumperz (1972) the bilingual speakers do not use language in the way they do simply because of their social identities or because of other situational factors, rather, they exploit the possibility of linguistic choices in order to convey intentional meaning of socio-pragmatic nature.

\section{Objective}

The aim and objective of the study is to have a survey on code-mixing in the languages of the anchors and the callers of the FM stations of the country and at the same time to analyze the reasons and patterns of the code-mixing.

\section{Methodology}

The following methods were followed to conduct the research.

\section{Recording Method:}

First of all, the programs of five individual days were recorded. The approximate time is 10 hours. And then all the code-mixed sentences 
and phrases have been identified and transcribed into English so that a fair analysis may be done to complete the research.

\section{Data Collecting Procedure}

To conduct the research, data were collected from the four main FMs of Bangladesh. To collect the data, the target groups were supplied with questionnaire. The target groups were the Radio Jockeys and the FM listeners. The questionnaire for RJs comprises five questions and the questionnaire for the listeners comprises seven questions on the related subject. Apart from this, some scholarly persons were asked to express their opinions on the code-mixing.

\section{Instrument}

A mobile phone having recording option was used to record the programs.

\section{Data Analysis and Findings of the Research}

The collected data have been analyzed in excel. The figures in the diagram charts are explained with the help of information provided by the respondents.

\section{Questionnaire for RJ}

Eight RJs from different FMs were questioned. Their responses are as follows:

\begin{tabular}{|c|l|c|c|c|c|}
\hline No & Questions & Yes & No & Sometimes & Probably \\
\hline 1. & $\begin{array}{l}\text { Do you mix Bengali and } \\
\text { English codes while } \\
\text { anchoring a program? }\end{array}$ & $50 \%$ & $12.5 \%$ & $37.5 \%$ & $25 \%$ \\
\hline 2. & $\begin{array}{l}\text { Do you think that the mixing } \\
\text { of Bengali and English codes } \\
\text { in conversation is a mark of } \\
\text { aristocracy and } \\
\text { modernization? }\end{array}$ & $75 \%$ & $50 \%$ & \\
\hline 3. & $\begin{array}{l}\text { Do you think that the use of } \\
\text { English with Bengali attracts } \\
\text { listeners? }\end{array}$ & $50 \%$ & & 5 \\
\hline
\end{tabular}




\begin{tabular}{|c|c|c|c|c|c|}
\hline 4. & $\begin{array}{l}\text { Do you think that the use of } \\
\text { English with Bengali in } \\
\text { anchoring a program is } \\
\text { necessary? }\end{array}$ & & $25 \%$ & $75 \%$ & \\
\hline 5. & $\begin{array}{l}\text { Do you think that the use of } \\
\text { English with Bengali is } \\
\text { harmful to Bengali? }\end{array}$ & $25 \%$ & $62.5 \%$ & & $12.5 \%$ \\
\hline
\end{tabular}

Figure 1.1: Percentage distribution for different questions of RJs and respondents' answers

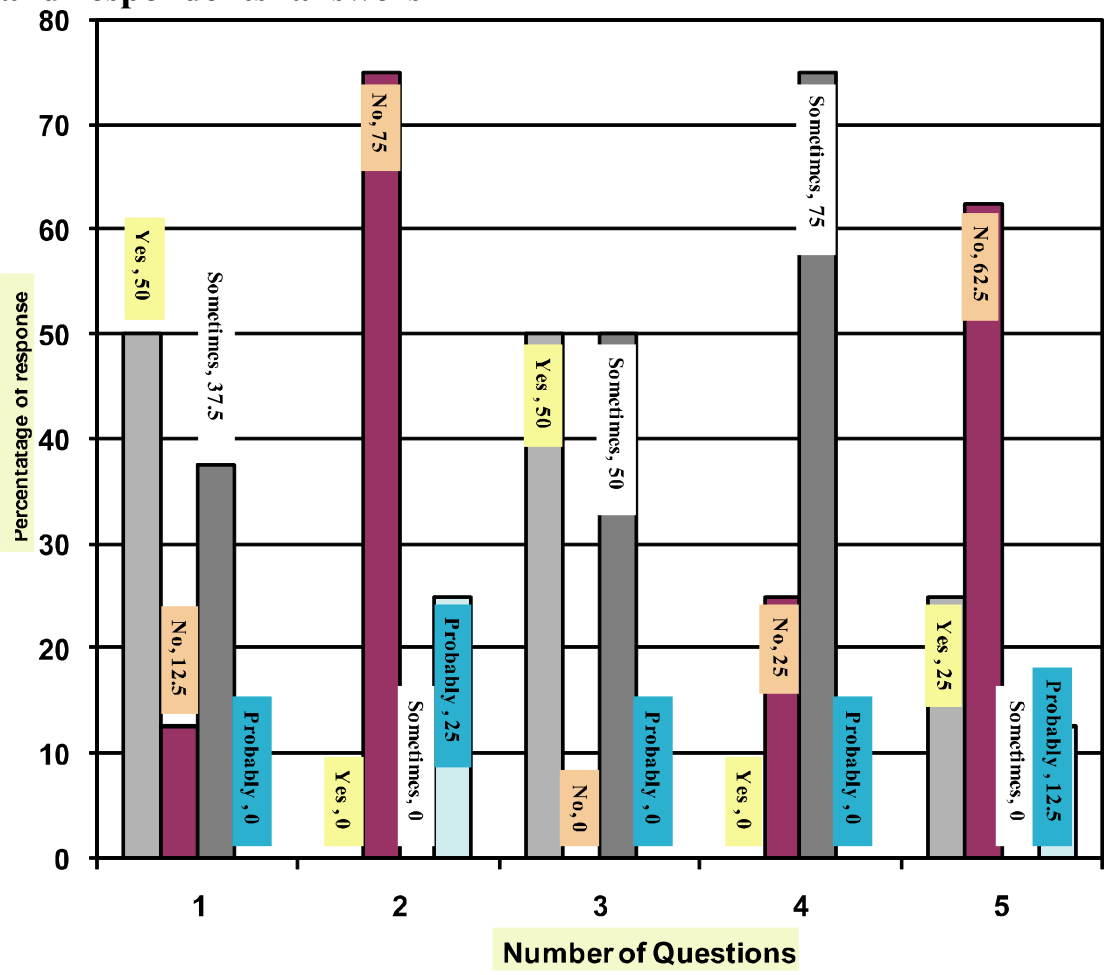

1. The first question shows that $50 \%$ RJs always mix Bengali and English while anchoring a program, $12.5 \%$ RJs never mix Bengali and English and 37.5\% sometimes mix Bengali and English.

2. The second question reveals that mixing English with Bengali is not a mark of aristocracy and modernism. Most of the RJs (75\%) do not use English with Bengali out of modernism and aristocracy, while the $25 \%$ of the RJs are not sure of it. 
3. The third question shows that the $50 \%$ of the RJs think codemixing attracts the listeners and the remaining 50\% think it does sometimes.

4. According to the fourth question, the $25 \%$ think that mixing English with Bengali is not necessary and the $75 \%$ thinks it sometimes is necessary.

5. The last one reveals that using English with Bengali, according to $25 \%$ is harmful for Bengali and the maximum (62.5\%) RJs do not think so, while $12.5 \%$ think it probably is harmful.

\section{Questionnaire for the listeners of FMs}

Forty FM listeners were questioned. Their responses are as follows:

\begin{tabular}{|c|l|c|c|c|}
\hline No & \multicolumn{1}{|c|}{ Questions } & Yes & No & Sometimes \\
\hline 1. & Do you listen to the FM radio? & $60 \%$ & & $40 \%$ \\
\hline 2. & $\begin{array}{l}\text { Are you aware of the mixing of Bengali } \\
\text { and English in the FMs? }\end{array}$ & $100 \%$ & & \\
\hline 3. & Do you support this mixing? & $20 \%$ & $80 \%$ & \\
\hline 4. & Is this mixing harmful for Bengali? & $60 \%$ & $10 \%$ & $30 \%$ \\
\hline 5. & $\begin{array}{l}\text { Do you think that the use of English } \\
\text { with Bengali is a mark of aristocracy? }\end{array}$ & $40 \%$ & $60 \%$ & \\
\hline 6. & $\begin{array}{l}\text { Do you think that the code-mixing is the } \\
\text { effect of globalization? }\end{array}$ & $90 \%$ & $10 \%$ & \\
\hline 7. & $\begin{array}{l}\text { Do you think that the code-mixing in } \\
\text { the FMs should be checked immediately } \\
\text { to protect Bengali? }\end{array}$ & $80 \%$ & $20 \%$ & \\
\hline
\end{tabular}


Figure 1.2: Percentage distribution for different questions of listeners and respondents answers

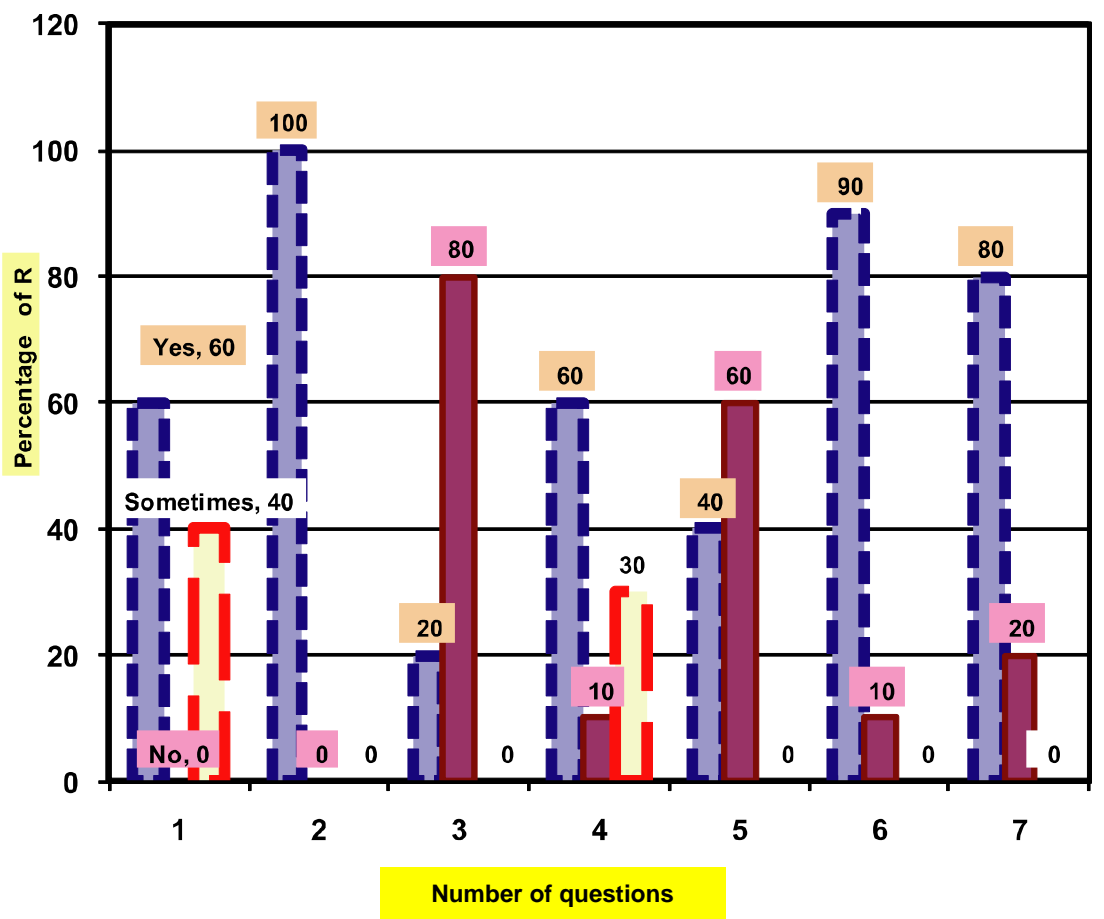

1. The first question; 'Do you listen to the FM radio?' shows that $60 \%$ respondents listen to $\mathrm{FM}$ radio regularly and $40 \%$ respondents do sometimes. As most of the respondents belong to young generation aging 20-25, this shows that almost all the youngsters listen to FM radio and it has been a great source of entertainment.

2. The second question; 'Are you aware of the mixing of Bengali and English in the FMs?' shows that 100\% respondents are conscious of code-mixing in the FM radio.

3. The third question; 'Do you support this mixing?' reveals that $80 \%$ respondents do not support code-mixing and only $20 \%$ support this mixing.

4. The fourth question; 'Is this mixing harmful for Bengali?' tells that $60 \%$ respondents think that code-mixing is harmful for Bengali and the $10 \%$ do not think so, while the remaining $30 \%$ think this mixing of Bengali and English is sometimes harmful. 
5. The fifth question; 'Do you think that the use of English with Bengali is the mark of aristocracy?' shows that $40 \%$ respondents think that mixing is some sort of aristocracy while other $60 \%$ do not think so.

6. The sixth question; 'Do you think that the code-mixing is the effect of globalization?' tells that $90 \%$ respondents think it as the effect of globalization and $10 \%$ do not support the idea.

7. The last question; 'Do you think that the code-mixing in the FMs should be checked immediately to protect Bengali?' shows that $80 \%$ respondents demand the immediate checking of this code-mixing while $20 \%$ do not demand it.

\section{Types of Code-mixing in the FMS}

From the recorded programs, the following selected code-mixings are chosen for discussion and analysis. The Bengali suffixes, words, phrases and sentences are in italics.

a) Lexicalization and Intra-word:

Song- $t a$ (the song)

Story-ta (the story)

Service-ta (the service)

Start-korona (to begin)

Restaurant- $e$ (in the restaurant) Friends-ke;

Number- $e$ (in the number);

shot- $e$ (in shot, term pertaining to film), etc.

b) Inter-word/Phrasal code-mixing:

--- Amar ajkey birthday, amakey wish korbey?

(Today is my birthday, will you wish me?)

--- Well ganta really josh.

(Well the song is really excellent.)

--- Tomar jonnay onek special kichu opeksha korchey. (Many special things await you.)

--- Traffic updates Dhakar chaka (Traffic update, the wheels of Dhaka)

--- Close up, kache asar golpo (Close up, the story of coming to a close relationship) 
--- Ajke Valentine's Day. Apnader kono special plan-ki royechey? (Today is the Valentine's Day. Do you have any special plan?)

--- Please play koro tumi amar ghum. (Please play the song: You are my sleep. Name of a favourite song in Bangladesh.)

--- So tumi taderkey dedicate-koroey song-ta play-koro. (So you play the song dedicating to them.)

--- Ami aj amar life-e protom sms korlam. (Today I have sent an sms to you for the first time.)

c) Sentential /Syntactic Code-mixing:

--- Ami udoykey onek onek love-kori. He is my love. (I love Udoy. He is my love.)

--- Kachey ashar golpo. This is very personal account. (Story of coming to a close. This is very personal account.)

--- Jara kaj korechilen. They were very professional. (Those who worked. They were very professional.)

--- Kibhavey jey ato complex akta bepar choto choto shot-e present korlo. I was really amazed.

(How did they present the complex matter in small shots? I was really amazed.)

--- How goes to real life? Amader listener-ke aktu bolben? (How goes to real life? Would you mind telling our listeners?)

--- Hey! all my friends, Welcome back. Amar shatey onek friends already jog diechey. (Hey! all my friends. Already many a friend has joined me.)

--- Hey! What's up? Please play. Tumi amar ghum. (Hey! What's up? Please play: You are my sleep.)

\section{Opinions of the Respondents}

Here are some comments from the persons who were interviewed about the mixing in the FM radio. The respondents are students, bankers, teachers, journalists etc. They have spontaneously expressed their opinions on the issue. Their comments are as follows:

a. Bengali is one of the richest languages in the world. At the same time English is an international language. And this is an age of 
globalization. So I think we should not be afraid of mixing English with Bengali.

b. In my opinion, mixing Bengali and English is not a mark of aristocracy rather it is a great problem for Bengali. That is why mixing should be prohibited.

c. The mixing of Bengali and English is important for us. Because we can easily learn English from mixing.

d. We should not mix Bengali and English together.

e. My view regarding code-mixing in FMs of $\mathrm{BD}$ is; it is neither detrimental to nor beneficial for our mother tongue rather it is an inevitable impact that any language of the developing countries around the world is experiencing. Time will decide weather it is simply a parasite or a devouring banyan.

f. The authority should take proper steps to avoid the mixing of Bengali and English. The RJs should not be allowed to mix Bangali and English.

\section{Motivations for Code-mixing:}

The motivations for code-mixing are basically of two types: attitudinal and linguistic. However, these two tend to coincide (Kachru 1978). The attitudinal code-mixing happens when people intend to show themselves off as prestigious ones. This is because in this sub-continent people get used to use English as aristocratic means of communication. This notion has made a room in the mind of the people since the British colonial rule. Nowadays English has been increasingly occupying the position of second language in Bangladesh. This trend is seen in the conversation and the anchoring in the FMs of Bangladesh. On the other hand, linguistic motivations for code-mixing are of three types: they are a) role identification, b) register identification, and c) desire for simplification and interpretation (Kachru 1978).

The parameters for role identification are social, registral, and educational. The languages which a multilingual person 'mixes' contribute to placing him/her in the hierarchy of social network in which s/he functions; code-mixing also marks his/her attitude and relationships towards the participants in speech act, and consequently, the attitudes of the other participants towards him (Kachru 1978). 
This study reveals that code-mixing in the FMs of Bangladesh is attitudinal. Because, there are neither linguistic difficulties, nor any circumstantial obligations that stand in the way of anchoring a program, rather they mix English with Bengali out of fashion and style.

\section{Attitude towards Code-mixing}

People's thinking is varied about code-mixing. Some people think that mixing English with Bengali is some sort of flamboyance and the exposition of colonized mentality. They always argue to decolonize the mind of the people about language. Apart from this, they think that Bengalese sacrificed their lives for mother tongue in order to protect its honor. If Bengali is adulterated with English, it will lose its individuality. Many scholarly persons think that code-mixing is detrimental for Bengali, because it will eclipse Bengali (Alam 2006).

Another group considers code-mixing as snobbery. They get disappointed and humiliated at the mixing of two languages. Wardaugh (1992) rightly says that people have mixed feelings of both appreciation and depreciation towards bilinguals.

A liberal group thinks that it is welcoming to mix English and Bengali in any situation because English is no longer a language of the English. It has been a part and parcel of daily life and through learning this language a nation can outshine in life, as the progress in science and commerce depend on learning this language. The RJs of the FMs belong to this group. They have taken English as second language and never feel hesitant in using English beside Bengali.

\section{Conclusion}

This research is a catalogue which manifests the circumstances of code-mixing in the FMs of Bangladesh. Though it is tough to make any comment on the merits and demerits of this mixing, from the above analysis, a thing is clear that the controversy will go on and at the same time code-mixing will also move on until and unless the conflict is synthesized by the judgment of time. In this regard a respondent's comment is worth quoting, "It is neither detrimental nor beneficial to Bengali rather it is an inevitable impact that the languages of the developing countries are experiencing. Time will decide whether it is simply a parasite or a devouring banyan. 


\section{References}

Alam, S. (2006), Code-Mixing in Bangladesh: A case study of NonGovernment white collar service Holders and Professionals. Asian Affairs, Vol. 28, No. 4, pp52-70

Banu, R \& Sussex, R. (2001), Code-Switching in Bangladesh. English Today 66, Vol 17, No 2, P-51.

Blom, J. P. \& Gumperz J. J. (1972). Social Meaning in Linguistic Structures: Code-switching in Norway. In J. J. Gumperz, \& D. Hymes (Eds.), Directions in sociolinguistics (pp. 409-434). New York: Holt, Rinehart, and Winston.

Hudson, R.A (1996), Sociolinguistics. Cambridge, Cambridge University Press.

Kachru, Braj, B. (1977), The Englishization of Hindi: language rivalry and language change to appear in I. Rauch et al.(eds.) Linguistic Method: Paper in Honor of Herbert Penzl. The Hague, Mounton.

(1978), Toward Structuring Code-Mixing: An Indian Perspective Vol. 16, EBSCO Publisher.

Wardaugh, R. (1992), An Introduction to Sociolinguistics. Oxford: Blackwell Publishers.

http://en.wikipedia.org/wiki/ABC_Radio_Bangladesh 